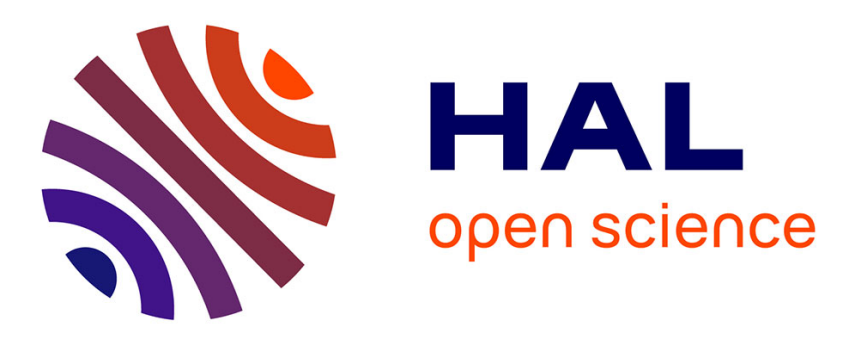

\title{
Optimisation of free-form surface machining using parallel planes strategy and torus milling cutter
}

Jean-Max Redonnet, Alejandro Gamboa Vázquez, Alberto Traslosheros

Michel, Stéphane Segonds

\section{- To cite this version:}

Jean-Max Redonnet, Alejandro Gamboa Vázquez, Alberto Traslosheros Michel, Stéphane Segonds. Optimisation of free-form surface machining using parallel planes strategy and torus milling cutter. Proceedings of the Institution of Mechanical Engineers, Part B: Journal of Engineering Manufacture, 2016, 232 (2), pp.240-250. 10.1177/0954405416640175 . hal-01913381

\section{HAL Id: hal-01913381 \\ https://hal.science/hal-01913381}

Submitted on 6 Nov 2018

HAL is a multi-disciplinary open access archive for the deposit and dissemination of scientific research documents, whether they are published or not. The documents may come from teaching and research institutions in France or abroad, or from public or private research centers.
L'archive ouverte pluridisciplinaire HAL, est destinée au dépôt et à la diffusion de documents scientifiques de niveau recherche, publiés ou non, émanant des établissements d'enseignement et de recherche français ou étrangers, des laboratoires publics ou privés. 


\title{
Optimisation of free-form surface machining using parallel planes strategy and torus milling cutter
}

\author{
Jean-Max Redonnet ${ }^{1}$, Alejandro Gamboa Vázquez ${ }^{2}$, Alberto Traslosheros Michel ${ }^{2}$ and \\ Stéphane Segonds ${ }^{1}$
}

\begin{abstract}
Machining by parallel planes is a widely used strategy for end milling of free-form surfaces on 3-axis Numerically Controlled (NC) machine. In industry, this type of machining is generally performed with a hemispherical tool. However, numerous studies have shown the benefits of torus end mill on ball end or flat end mills. More than anything, the machining direction has much influence on productivity while using a torus end mill. In this context, the choice of the machining direction is of paramount importance when using a torus end mill in machining of free-form surfaces. This paper presents an optimisation of part machining direction allowing minimizing the machining time within the respect of the maximum imposed scallop height. This optimisation methodology is then applied to an industrial part and measurements are performed on this part. The study highlights the interest of optimizing the machining direction and the benefits that can be drawn with respect to machining using a no optimized direction.
\end{abstract}

\section{Keywords}

free-form surface, CNC machine-tool, torus-end mill, effective tool radius, workpiece orientation, optimisation

\section{Introduction}

Machining by parallel planes ${ }^{1}$ is a common strategy for the machining of freeform surfaces on 3-axis $\mathrm{NC}$ machine tool, especially for the production of molds and dies. It is widely used in industry because it is reliable and robust, well-proven through years of practice. Indeed, this strategy allows on one hand to leave no uncut areas of the part, and on the other hand to ensure that the generated tool paths do not intersect (which is significant in terms of productivity).

When finishing freeform surfaces, the main criterion for assessing the quality of the machining is the scallop height, denoted $s_{h}$ (see figure 1). During machining of a rough surface, a ridge, formed by the residual material between two successive paths of the tool, appears regardless of the type of tool used: flat-end, ball-end or torus-end mill. The height of this scallop is a critical parameter because it gives an indication on the amount of material which has to be removed by polishing operations that are done after the machining finishing operation. It mainly depends on the step over distance (denoted $s_{o d}$ ) which is the distance, in a plane normal to the feed direction, between two successive paths of the tool.

In industry, the machining strategy by parallel planes is usually implemented using a ball end mill. However, numerous studies have demonstrated the opportunity of using a torus-end mill rather than a hemispherical or flatend mill ${ }^{2-6}$. Indeed, as the flat-end tool, the torus-end mill allows under certain conditions, for a given step over distance, to obtain a lower scallop height than that allowed by the ball-end one. For a given scallop height (i.e. at constant quality), it saves then a lot of productivity. In addition, the torus-end mill avoids unsightly marks left on the part by flat-end tool and preserves the surface integrity ${ }^{7}$. By combining the benefits of both of flat-end and ball-end tools, torus-end mill appears to be the ideal compromise for finishing operation by end milling of freeform surfaces.

The relationship between machining direction, step over distance and tool geometry is well known ${ }^{8}$. Figure 2 illustrates this relationship for both ball-end and torus-end mills. This clearly highlights the fact that the torus-end tool is far more efficient when machining in the direction of greatest slope while it is less efficient when machining in a direction perpendicular to the direction of highest slope.

\footnotetext{
${ }^{1}$ Université de Toulouse; Institut Clément Ader, Toulouse, France

2 Universidad Aeronáutica en Querétaro, México

Corresponding author:

Jean-Max Redonnet, Université de Toulouse; Institut Clément Ader, 3 rue Caroline Aigle, 31400 Toulouse, France.

Email: jean-max.redonnet@univ-tlse3.fr
} 
The tool moves in the di-
rection perpendicular to the
plan of the figure.

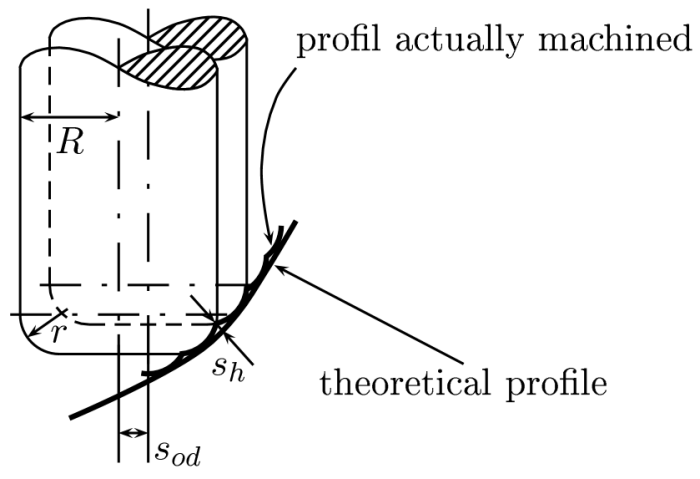

Figure 1. Scallop height

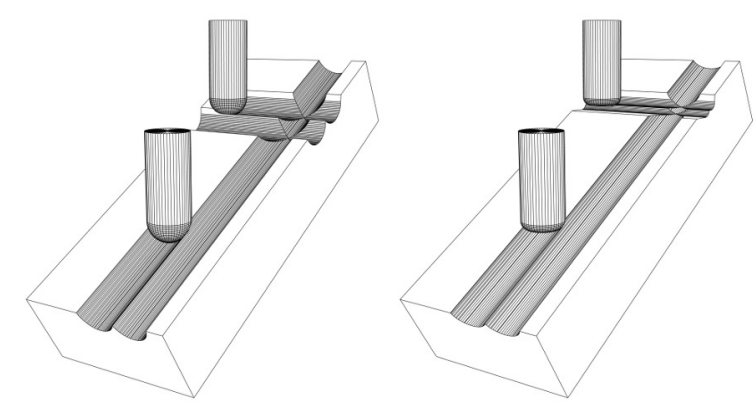

Figure 2. Relationship between machining direction and step over distance using a ball-end mill (left) and a torus-end mill (right)

But while the max slope direction is quite obvious for a plane, like in Figure 2, in the case of a free-form surface, this direction is different for each point. Thus, the best direction for the whole surface cannot be determined easily.

$\mathrm{In}^{9}$, the authors show that even in the case of a ball end mill, the machining direction is one of the most influential parameters on the machining time. In this case the tool effective radius (see section Context page 3 for comprehensive definition of effective radius) is invariant and only the angle between the direction of maximum slope and machining direction influences. In the case of torus-end mill use, this parameter is even more influential since the effective radius of the toric profile which leaves traces in the material varies with the working direction. For a torus end mill of major radius $R$ and torus radius $r$, effective radius varies between $r$ and infinity.

These considerations show that efficiency of torus-end mill is highly affected by the machining direction. Thus, this direction have to be carefully choosen to be relevant for the whole surface machining.

For 3-axes machining the milling direction is defined by position and orientation of the workpiece. Indeed, the issue of position and orientation of the workpiece is often considered in terms of dynamic behavior of the machine ${ }^{10-12}$, or from the viewpoint of the visibility of surface to be machined ${ }^{13 ; 14}$. Few studies address the issue of the optimal machining direction. Among them may be mentioned $^{9}$, which is confined to the use of a ball-end tool. But these approaches are all based on local parameters and do not consider the surface as a whole. Therefore they are limited to provide the optimum machining direction at a point of the surface or calculating a first optimal path ${ }^{15 ; 16}$. If they are, for most of them, relevant and meaningful, their extension to the whole surface is not the result of a real optimisation process.

Other authors consider optimisation of freeform surface machining process from other points of view than productivity. For example in ${ }^{17}$, the authors seek to optimize the quality of the surface using neural networks. Others seek to optimize the machining quality by adjusting the feed rate of the tool ${ }^{18-20}$.

In the context of machining free-form surface with a torus-end mill, global process optimization using total machining time as objective function has not already been studied.

Our study is thus conducted in the context of 3-axis machining by parallel planes with a torus-end mill. The objective of this study is to minimize the machining time while maintaining a maximal scallop height constraint respected. At first, we neglect dynamic effects and it is considered that the machining time is directly proportional to the length of the tool path. Other work in the laboratory ${ }^{21}$ showed that this approximation is quite valid for the machining of freeform surfaces in most configurations.

\section{Contribution of this paper}

While machining using parallel planes strategy, the direction of the machining plane is of paramount importance as it is, with the direction of maximum slope of 
the surface, a key parameter in the value of the tool effective radius. To date, however, there is no method for determining the machining direction that have to be used to machine a freeform surface with a torus end-mill in a minimum time.

The main contribution of this paper is thus to provide a procedure for determining the machining direction that have to be used to machine a freeform surface with a torus end-mill in a minimum time.

The machining of the freeform surface is time consuming, especially during finishing, so this method could provide increased productivity. It is noticable that as far as we know no optimisation process of the milling direction is proposed by any commercial CAM software, especially using a toroidal cutter.

From an optimization point of view this problem can be stated as follows :

$$
\begin{aligned}
& \text { Min } \quad \text { toolpath_length }(\theta) \\
& \text { s.t. } \quad s_{h i} \leqslant s_{h \max } \quad \forall i
\end{aligned}
$$

where the optimisation variable $\theta$ is the angle between the $X$ axis of the machine and the vector $\mathbf{F}$ and $i$ is the index of the points of the tool path (see figure 3 ). In this publication, it is shown how this optimisation can be implemented and the potential benefits it can bring.

Therefore, the computation time of a path planning for the entire surface must be low enough to allow the integration of this process with the goal of optimisation. It then will therefore becomes possible to solve in a reasonable time the optimisation problem (1).

Furthermore this optimisation problem is subject to numerous inequality constraints. Indeed for each point of the planed toolpaths the maximum scallop height allowed must be respected. The seconds objective of this paper is to ensure that these constraints are respected. In other words, the procedure we propose must ensure quality respectfull.

To ensure both of these objectives are respected we first propose a new procedure to determine optimum machining direction while respecting tolerance. Then, on a test case, we apply this procedure and verify maximum scallop height is actually respected by measuring the machined part.

\section{Context of this study}

A key parameter in the generation of machined scallops is the effective radius of the tool denoted $R_{e f f}$, which can be defined as the projection in a plane normal to feed direction, of the trace left by the tool into the material ${ }^{22}$. Indeed, the effective radius of the tool is characteristic of scallop height $s_{h}$. Denoting $d$ the distance defining the next parallel plane position, the step over distance $s_{\text {od }}$ can be readily determined as it is directly related to $d$ by angle $\gamma$ characterising the local inclination of the surface in a plane normal to the machining direction (figure 4). Showing that the step over distance is directly related to the cutter effective radius is thus equivalent to showing that distance $d$ depends directly on that effective radius. Well as proven in $^{22}$ the distance $d$ can be calculated by

$d=\frac{\sqrt{\left(4 R_{e f f}^{2}+4 \varrho R_{e f f}-2 s_{h} \varrho-s_{h}^{2}\right)\left(2 \varrho+s_{h}\right) s_{h}}}{\varrho+s_{h}}$

where $\varrho$ is the local curvature of the surface

For a given machining plane, the position of the adjacent plane is defined by the value of the transverse step over distance $s_{\text {od }}$. This value is calculated using the maximum permissible value of the scallop height at the worst of the trajectory points. In other words, at this point, the scallop height between two adjacent planes is equal to the maximum allowable value, while at all other points of the trajectory the scallop height are less than the maximum permissible value.

In a previous study ${ }^{22}$, a novel approach to calculate analytically the effective radius of a torus milling cutter moving in pure translation is presented. This approach is based on the two following lemmas :

Lemma 1. Let $\mathcal{P}$ be the mathematical operation for projection along the feed direction $\mathbf{F}_{\mathbf{t}}$ in a plane normal to $\mathbf{F}_{\mathbf{t}}$. Let $\mathbf{T}_{\mathbf{p}}(v)$, be the curve resulting from the projection along $\mathcal{P}$ of the cutter envelope. Let $\mathbf{E}(t)$ be the ellipse resulting from the projection along $\mathcal{P}$ of the cutter centretorus circle, and $\mathbf{o E}(t)$ an offset exterior to that ellipse with a value equal to the radius of the cutter torus. Then the two curves $\mathbf{T}_{\mathbf{p}}(v)$ and $\mathbf{o E}(t)$ are coincident.

Lemma 2. The radius of curvature of a plane offset curve is equal to the radius of curvature of the original curve augmented by the offset value.

Once demonstrated these lemmas, the effective radius of the toroidal cutter can be calculated considering the projection of the torus center circle in a plane normal to the machining direction and the $r$-offset of the resulting ellipse. The validity of this approach is fully demonstrated in ${ }^{22}$. It is also stated that this demonstration is only valid for pure translation movement of the cutter.

Simple analytical formula (2) resulting of this study saves considerable time in the calculation of the effective radius of the tool and thus the scallop height resulting from two side by side tool paths. Indeed, the only known alternative to accurately assess the scallop height is through numerical calculation of the intersection between the two envelope volumes of tool paths. The calculation time is considerably shortened using a simple analytical formula allowing to consider applications banned until now due to their cost in terms of computation time.

The parallel planes machining strategy (figure 3 ) is used to define each tool path as the intersection of the tool-center 

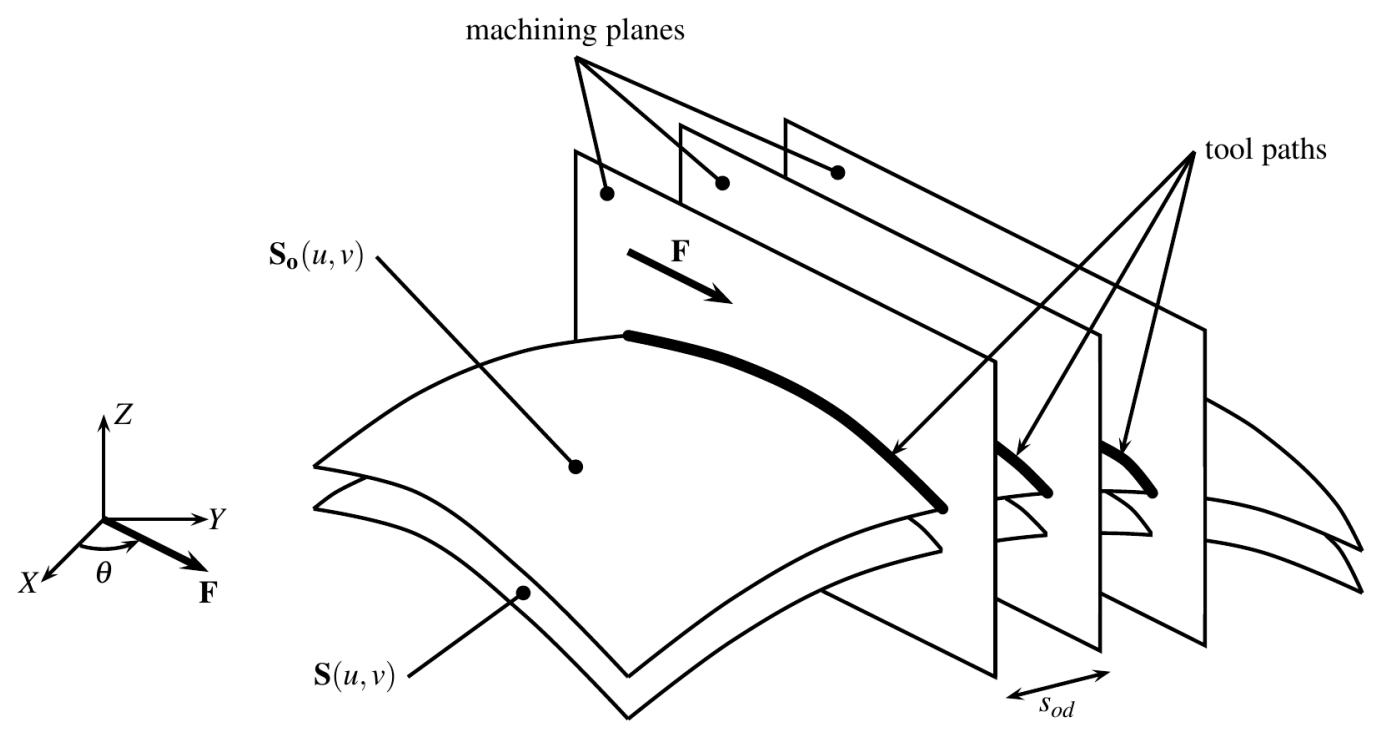

Figure 3. Machining strategy by parallel planes

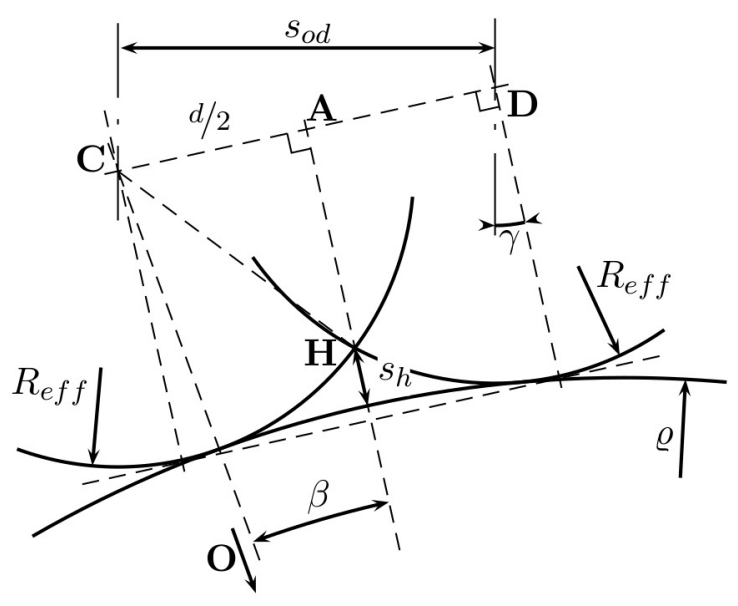

Figure 4. Step over distance calculation

surface and a vertical machining plane oriented along an overall machining direction that is called $\mathbf{F}$. For torus end mill, the tool-center surface is defined by:

$$
\mathbf{S}_{\mathbf{o}}(u, v)=\mathbf{S}(u, v)+r \mathbf{n}(u, v)+(R-r) \mathbf{n}_{\mathbf{p}}(u, v)
$$

with

$$
\mathbf{n}_{\mathbf{p}}(u, v)=\frac{\mathbf{Z} \times(\mathbf{n}(u, v) \times \mathbf{Z})}{\|\mathbf{Z} \times(\mathbf{n}(u, v) \times \mathbf{Z})\|}
$$

where $\mathbf{S}(u, v)$ is the surface to be machined and $\mathbf{n}(u, v)$, the unit normal to the surface in $(u, v)$.

For simplicity, we consider the vector $\mathbf{F}$ in the $(X, Y)$ plane of machine axes, i.e. the direction of $\mathbf{F}$ corresponds to the projection of $\mathbf{F}_{\mathbf{z}}$, feed direction vector in the plane $(X, Y)$ :
The analytical expression of the effective radius of a torus-end mill moving in translation is ${ }^{22}$ :

$$
R_{e f f}=\frac{(R-r) \cos (\alpha)^{2}}{\sin (S)\left(1-\sin (\alpha)^{2} \sin (S)^{2}\right)}+r
$$

where $S$ is the slope of the workpiece surface at the tool/workpiece contact point and $\alpha$ the angle between the direction of steepest slope projected in the plane $(X, Y)$ and the vector $\mathbf{F}$. It can be noted that if $R=r$, equation (2) corresponds to the well-known expression of effective radius for ball-end mill cutter. Using this formula, the calculation of step over distance $s_{o d}$ at a point can be done instantly compared to the numerical methods previously used that required an important computation time.

\section{Optimization methodology and implementation}

\section{Optimisation algorithm}

As posed in (1), the problem that is proposed to be solved is a nonlinear constrained optimisation problem. The main difficulty is the evaluation of the objective function as it requires the full simulation of a machining planning for the entire surface. Considering $i$ the point index of a given path, and $j$ the index of the path, are defined:

- $\mathbf{P}(i, j)$ the $i^{\text {th }}$ point of the path $j$

- $p(j)$ the position of the plane containing the path $j$ in the direction perpendicular to the machining planes.

- $s_{\text {od }}(i)$ the step over distance value calculated for a point $i$ of a given path so that the scallop height criterion is respected. 
- $s_{\text {odp }}(j)$ the value of the step over distance used to calculate the position of the next plan, i.e. $p(j)=$ $p(j-1)+s_{\text {odp }}(j)$. For a given path, $s_{\text {odp }}(j)$ should be defined as $s_{\text {odp }}(j)=\operatorname{Min} s_{\text {od }}(i)$ to be sure to respect the scallop height criterion.

- length $(j)$ the length of the path $j$

The evaluation of the objective function then proceeds as described in algorithm (1). This algorithm is also presented as a flow chart in figure 5 .

This evaluation process of the objective function effectively enforced all conditions $s h_{i} \leqslant s h_{\max } \forall i$ whatever the value of the variable optimisation $\theta$ should be. It allows integrating the optimisation problem constraints (1) into the objective function.

To carry out the optimisation procedure itself, it is then possible to use an unconstrained optimisation algorithm. We chose the Nelder-Mead algorithm ${ }^{23}$ because it is known for its robustness and efficiency, due at least in part, to the fact that it does not require calculation of derivatives. Its main drawback, commonly accepted, is that it progresses relatively slowly compared to algorithms including the calculation of derivatives. It may be noted that in the context of our problem, the evaluation of derivatives require the full calculation of a machining planning, which significantly lengthen the overall time resolution.

Furthermore, the optimisation procedure described in algorithm 1 also provides a complete and optimized planning for finishing of the surface, which is an advantage over a procedure that would only provide the optimal machining direction.

In terms of computation time, the whole process optimisation / planning requires a few seconds to tens of seconds depending on the chosen parameters. The most influential parameters are:

- The scallop height $s_{h}$ : the smaller it is and the more the machining planes will be close the one to others, resulting in the calculation of a larger number of machining paths. A value commonly used in the industry is $0.01 \mathrm{~mm}$.

- The required accuracy on the optimisation variable $\theta$. For our calculations we used an accuracy of 1 degré. degree. Run the optimisation procedure with superior accuracy generates greater computation time without making any significant gain in productivity.

\section{Implementation}

In order to determine the starting point of the optimisation procedure, a rough estimate of the first objective function is performed for a set of values covering the solution domain. In practice, the objective function is evaluated every $5^{\circ}$, between $-90^{\circ}$ and $+90^{\circ}$, simulating a machining operation with a $0.1 \mathrm{~mm}$ scallop height. If it is not exactly realistic for industrial application, this value $(0.1 \mathrm{~mm})$ provides very quickly (about ten seconds) an acceptable starting point for the optimisation procedure.

From this starting point, a first simplex is automatically generated and optimisation itself begins (see algorithm 1).

The test environment has been developed in Java.

\section{Application to a real case: Machining a boat propeller blade}

\section{Introduction}

The determination of the optimal machining direction for end-milling of a free-form surface with a torus-end mill using parallel planes machining strategy allows to significantly increase the productivity. Of course, the time savings that are to be expected depend largely on the geometry of the surface. For example, the application of the previously detailed optimisation procedure to a complex surface from an industrial environment is presented. This surface, taken from a boat propeller measuring $293 \mathrm{~mm}$ in diameter (Fig. 6), is constituted by the upper surface of a blade (Fig. 7). When it is defined by a ruled surface, this type of part can be machined using side milling process ${ }^{24}$, but this one is defined by a $8 \times 8$ Bézier surface. The best choice to manufacture it is then to mill it using a end mill strategy.

Simulations and real part machining were carried out using a torus-end mill of major radius $R=5 \mathrm{~mm}$ and torus radius $r=2 \mathrm{~mm}$.

The manufacture of the workpiece from the trajectories calculated by the optimisation procedure has been implemented with a zigzag trajectory planning. Before the finishing operation, a roughing and a contouring phase have been completed (Fig. 8).

The finishing operation was conducted using a spindle rotation of $7950 \mathrm{rpm}$ and a feed-rate of $1600 \mathrm{~mm} / \mathrm{min}$.

\section{Results and discussion}

\section{Machining time}

Using a $0.01 \mathrm{~mm}$ scallop height parameter, the total duration of the optimisation process is 116 seconds for the tool $(R=5 \mathrm{~mm} ; r=2 \mathrm{~mm})$. The obtained optimal value of the angle is $\theta^{\star}=-27.53^{\circ}$. The path length of the machining is $12315 \mathrm{~mm}$.

The machining planning obtained by the optimisation procedure is shown in figure 9 .

Considering the scallop height value $\left(s_{h}=0.01 \mathrm{~mm}\right)$ for the finishing operation, the trajectories are so close to each other that representing all of them in this figure would make it unintelligible. To maintain readability of this representation, we have chosen to represent only one path over five. 


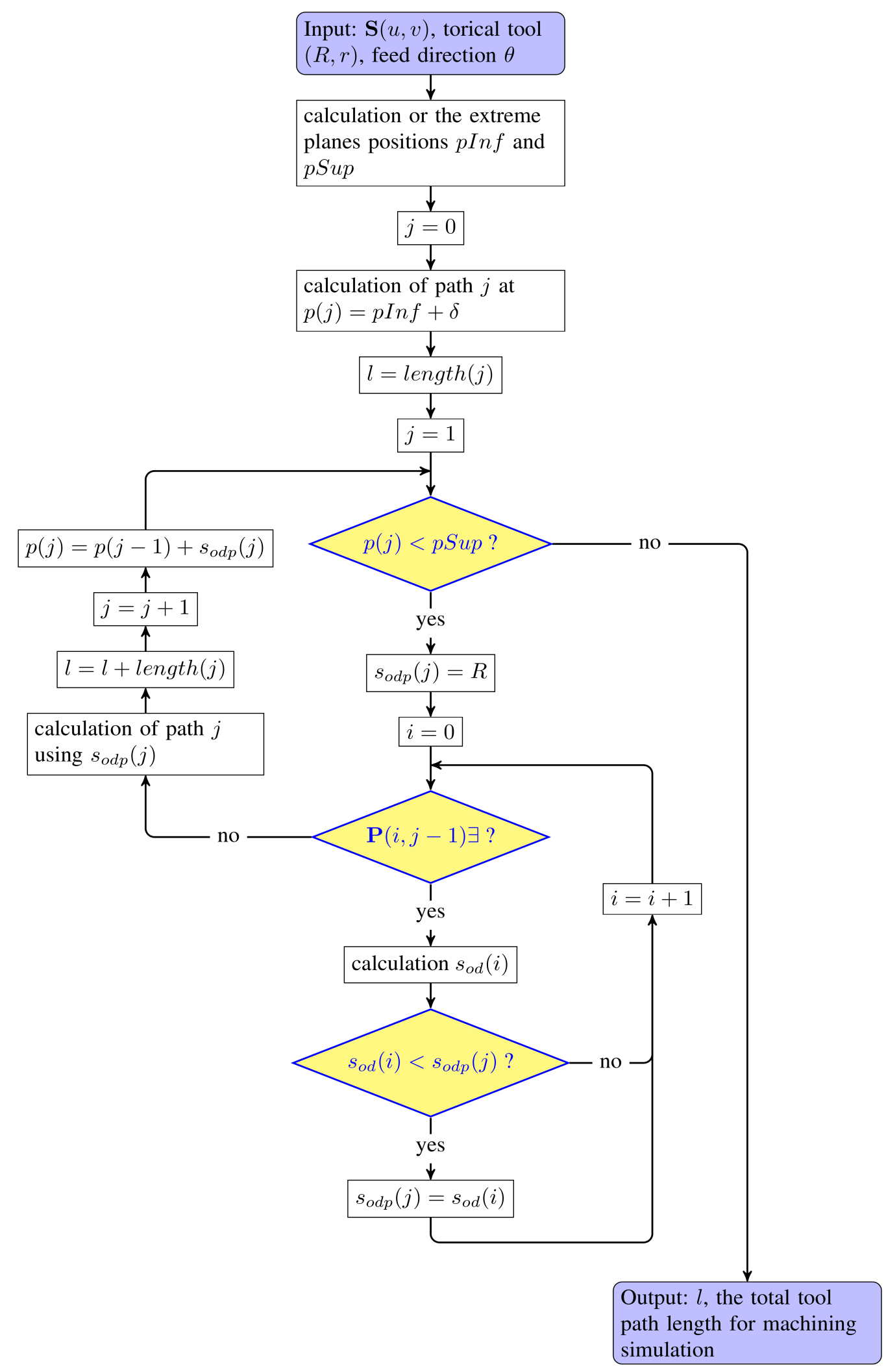

Figure 5. Flowchart representation of the algorithm 
Data: A surface $\mathbf{S}(u, v)$, a torical tool $(R, r)$, a feed direction $\theta$

Result: $l$, the total tool path length for a machining simulation calculation of the position of extreme planes $p I n f$ and $p S u p$ $j=0$

calculation of the first path with $p(0)=p \operatorname{In} f+\delta$

$$
\text { /* } \operatorname{pInf}<p(j)<p S u p \quad \forall j \star /
$$

$l=$ length $(j)$

$j=1$

while $p(j)<p$ Sup do

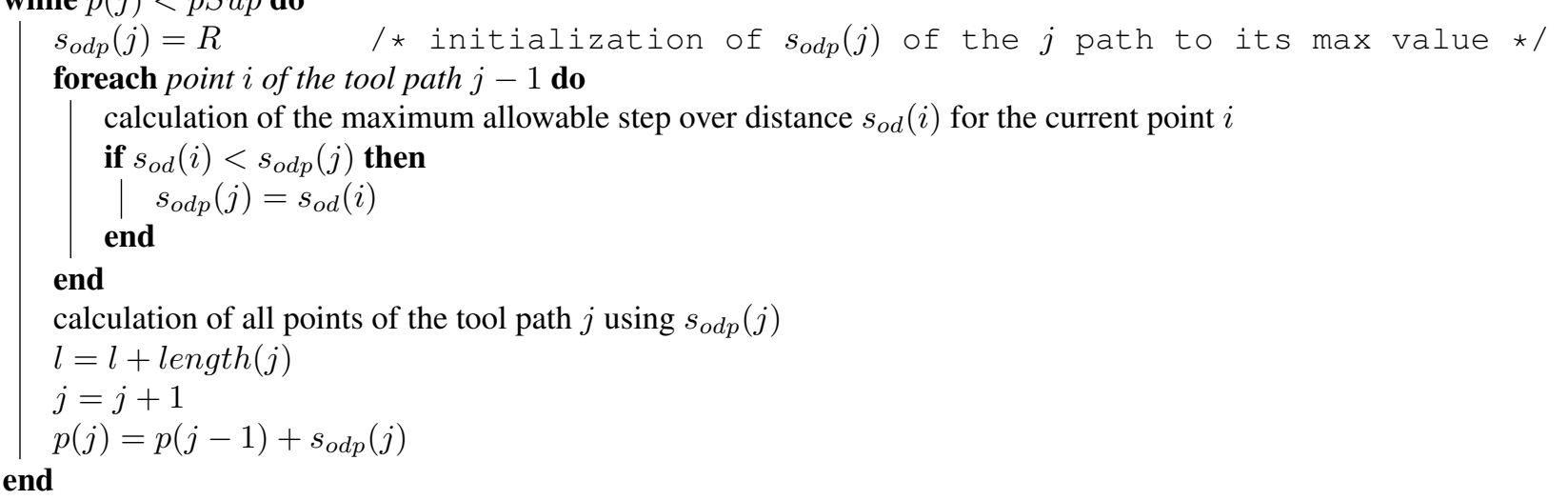

Algorithm 1: Evaluation of the objective function

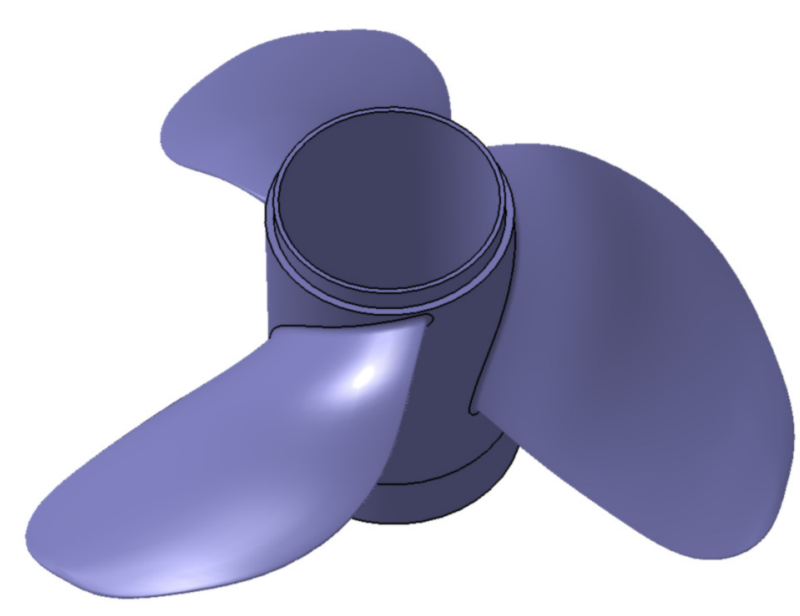

Figure 6. Boat propeller

Using the parameters described above (section Application to a real case page 5), the total duration of the machining cycle was $8 \mathrm{~min}$ and $16 \mathrm{~s}$. The such machined workpiece is shown in figure 10 .

The results presented here can give an idea of the potential gains that allows the optimisation of the machining direction during milling of the free-form surfaces using parallel planes strategy with a torus end-mill. The diversity of complex surfaces coming from CAD is such that no analysis of the performance of a machining algorithm can be generalized. So the potential contribution

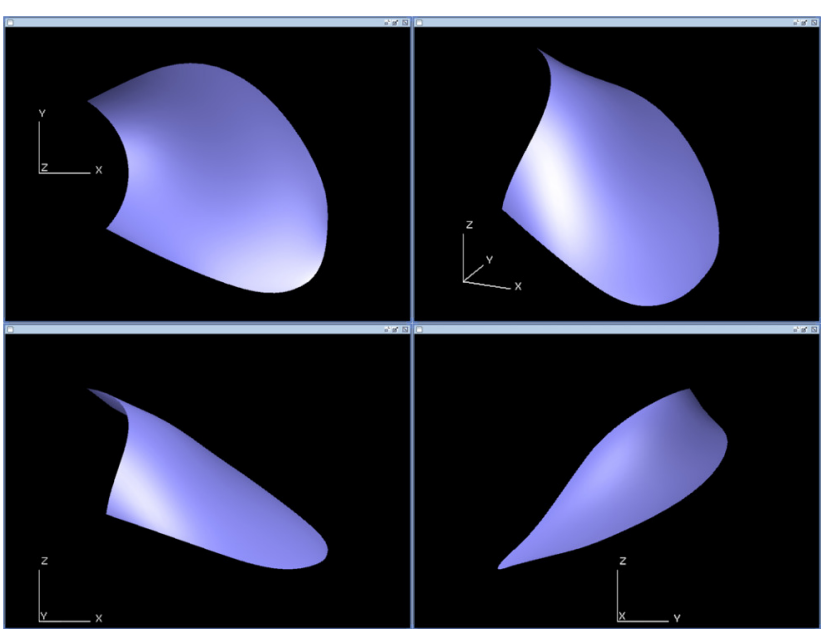

Figure 7. Upper surface of the blade

of this procedure is necessarily evaluated through an example.

To evaluate the potential gain, the results of the machining planning for the entire domain of definition of the parameter $\theta$ are compared. These results are shown in figure 11.

By various tests, it has been found that for this surface, the total duration of the procedure is about 2 minutes.

To evaluate the potential gain that prior calculation of the optimal machining direction can offer, the most favorable case and the worst case are compared (Table 1): 
Table 1. Comparison between extreme cases for a single part

\begin{tabular}{|l|c|c|}
\hline & Most favorable case & Worst case \\
\hline angle $\left({ }^{\circ}\right)$ & -27.53 & -80 \\
path length $(\mathrm{mm})$ & 12315 & 17301 \\
calculus duration (s) & 116 & 3 \\
calculus duration (hh : mm : ss) & $00: 01: 56$ & $00: 00: 03$ \\
machining duration (s) & 496 & 697 \\
machining duration $(\mathrm{hh}: \mathrm{mm}: \mathrm{ss})$ & $00: 08: 16$ & $00: 11: 37$ \\
programmed feed-rate $(\mathrm{mm} / \mathrm{min})$ & 1600 & 1600 \\
effective feed-rate $(\mathrm{mm} / \mathrm{min})$ & 1490 & 1490 \\
total duration $:$ calculus+machining $(\mathrm{hh}: \mathrm{mm}: \mathrm{ss})$ & $00: 10: 12$ & $00: 11: 40$ \\
\hline
\end{tabular}
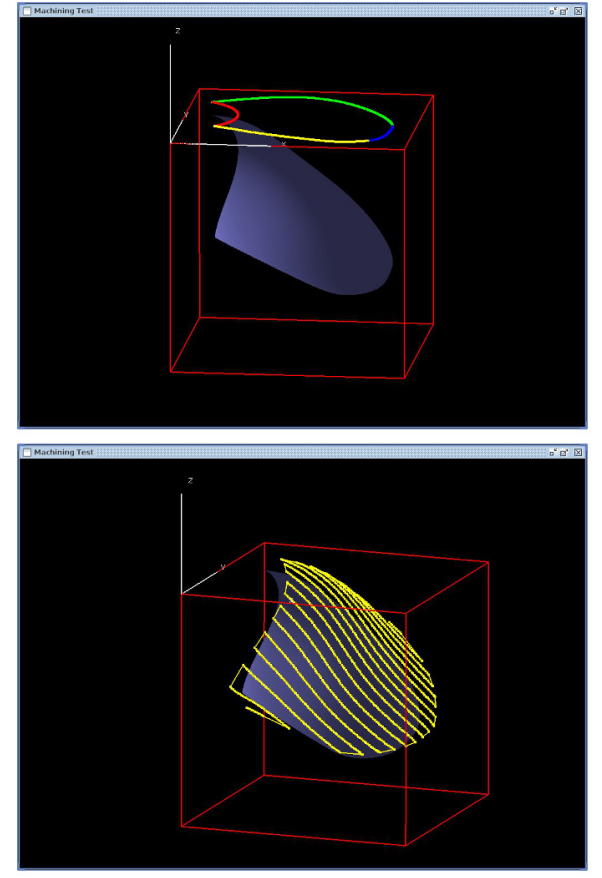

Figure 8. Contouring and roughing preliminary operations

This comparison highlights several interesting points:

- for this workpiece, the potential gain can rise up to $1-\frac{12315}{17301}=0.288=28.8 \%$

- for this workpiece, the total duration of the procedure including optimisation (calculus plus machining) is less than the total length of the simple machining procedure in the worst case. In other words, the optimisation of the machining direction saves time since the machining of the very first part. Of course our procedure saves even more time than the series is important. Indeed, the procedure for determining tool paths is performed only once while the machining time saved occurs on every workpiece. For example, on the workpiece studied here for the realization of a series of 50 pieces, the total time savings could

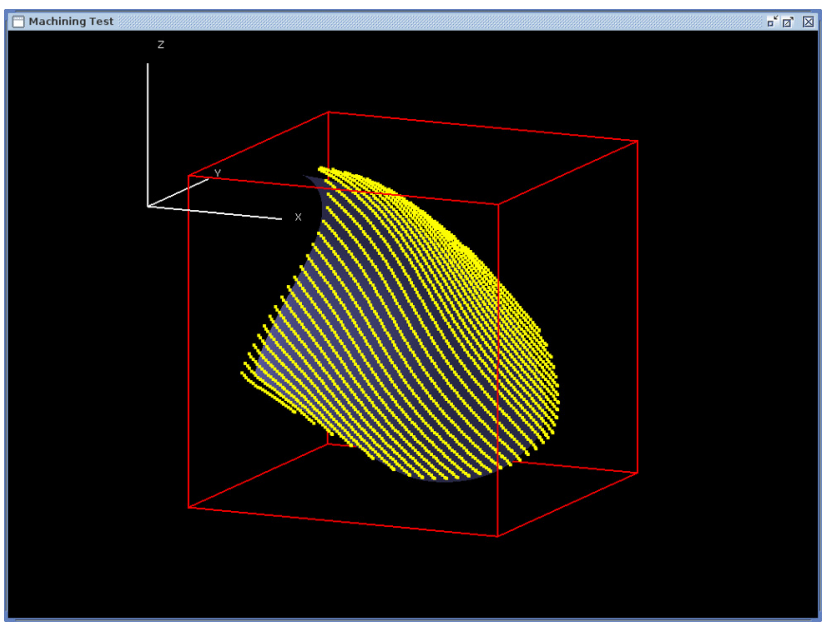

Figure 9. Machining tool path planning along optimal direction (1 path over 5 is drawn)

be up to $2: 45$ hours. (picking values in Tab. 1, we can state time saved is $(697-496) \times 50-(116-$ 3) seconds ).

This example allows highlighting the interest to optimize the machining direction before the completion of part machining itself. In addition, the comparison is limited to measurements of time. In terms of manufacturing costs, the hourly computing rate is far less than the hourly machining rate; the interest of the presented procedure is then even more evident.

It should however be noted that the numerical values in the presented results include only one example. Since each piece of CAD is special case, no overall performance value can be advanced. The example that is discussed here, however, allows highlighting the potential value of the detailed procedure. With this in mind, this surface has several attractive features:

- it is an industrial workpiece

- the optimal machining direction is not obvious $a$ priori

- it has wide variations in normal direction 


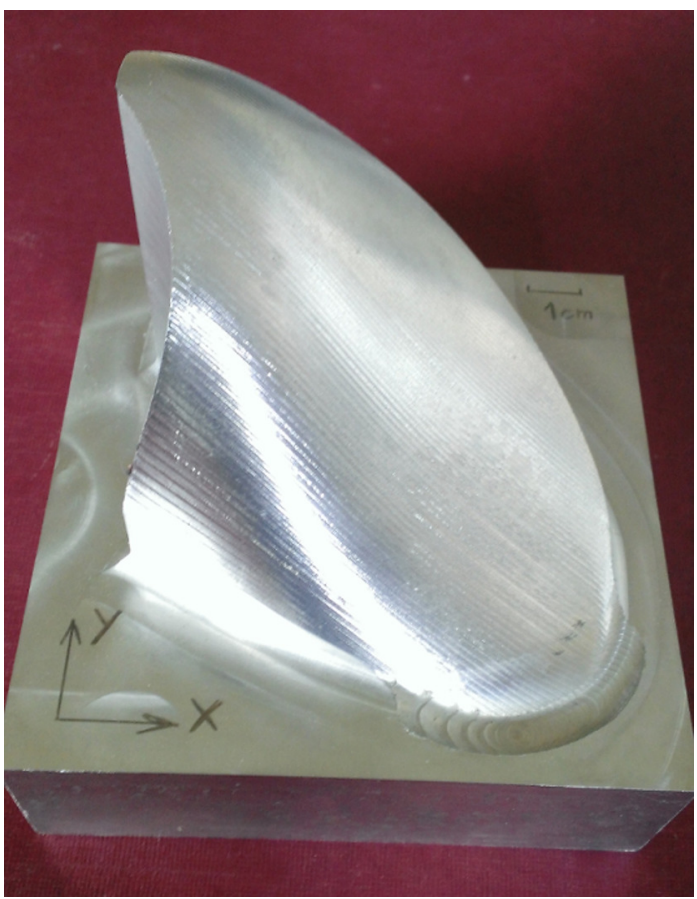

Figure 10. Machined part

For all these reasons, this area is representative of the forms commonly encountered in the modeling of molds and dies; so it is a good example to illustrate the performance of the presented procedure.

\section{Surface quality}

To check the validity of the machined part, we conducted a series of measurements at different points of the part. Special attention have been paid to focus the measurements in the most critical areas. Indeed, as mentioned in section Context page 3, during the machining of a curved surface with parallel planes strategy, all the different points of the path do not generate the same scallop height and it is the most critical point that determines the position of the adjacent plane.

To make these measurements, a 3D optical Alicona Infinite SL was used.

Figure 12 shows one of these measurements results. This figure highlights the scallops that are typical of a free-form surface machining. On this screnshot, the left scallop is fully measured between left and $19.059 \mathrm{~mm}$ and $19.069 \mathrm{~mm}$. The maximum allowable scallop height is $0.01 \mathrm{~mm}$, it can be said that tolerance is respected at this point. In the same figure the right scallop is fully measured between $19.056 \mathrm{~mm}$ and $19.066 \mathrm{~mm}$. At this measurement point, geometric specification is also respected.

On the whole part, 10 measurements were made and similar results were found for all these measures, i.e. that tolerance is respected at each measured point. We can therefore say that the tool paths calculated by the presented algorithm (see algorithm 1) allows to respect the constraints of our optimization problem (see equation 1), i.e. maximum allowable scallop height. The validity of the presented optimization procedure is therefore confirmed by experimentation.

\section{Conclusion and perspectives}

In this article, a procedure to determine the optimal machining direction using parallel planes strategy and torus end-mill is presented. This optimal direction is the one that allows the greatest productivity while respecting the maximum scallop height constraint. This methodology has several advantages: first, it is simple to implement because it is based on a simple optimisation algorithm. Also it provides quick results and full toolpath planning in the context of machining freeform. This simplicity of implementation and speed make this an easy procedure to integrate into a workflow process.

The optimisation procedure we propose has been validated on a test case. This experiment shows the potential gain that can be obtained using it.

For moment our method is only applied for parallel planes strategy. We are currently working on improvments to be able to apply this method to other machining strategies. This will be the purpose of future publications. For this publication, we choose the parallel planes strategy because it is widely used in industry (most people choose it because it is reliable and efficient) and the optimisation problem is quite simple to state (it depends only on one optimisation variable: the feed direction $\theta$ ).

To improve the procedure that is presented here, it is also planned to integrate the dynamic behavior of the CNC machine in order not to optimize the distance traveled by the tool but the total machining time. In addition, it is also proposed to test and / or develop other optimisation algorithms in order to improve the computation time.

\section{References}

1. Park SC and Choi BK. Tool-path planning for directionparallel area milling. Computer-Aided Design 2000; 32(1): 17-25. DOI:10.1016/S0010-4485(99)00080-9.

2. Bedi S, Ismail F, Mahjoob MJ et al. Toroidal versus ball nose and flat bottom end mills. The International Journal of Advanced Manufacturing Technology 1997; 13(5): 326-332. DOI:10.1007/BF01178252.

3. Jensen CG and Anderson DC. Accurate tool placement and orientation for finished surface machining. Journal of Design and Manufacture 1993; 3: 251-261.

4. Redonnet JM, Rubio W, Monies F et al. Optimising tool positioning for end-mill machining of free-form surfaces 


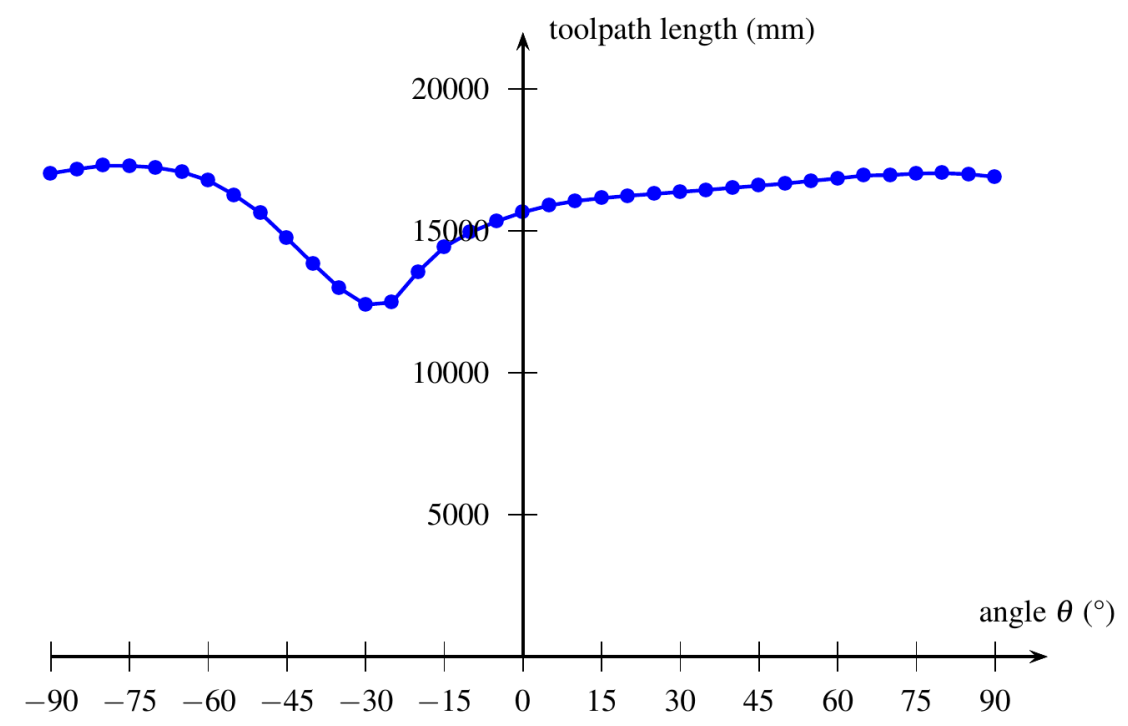

Figure 11. Evolution of the objective function value on the whole domain

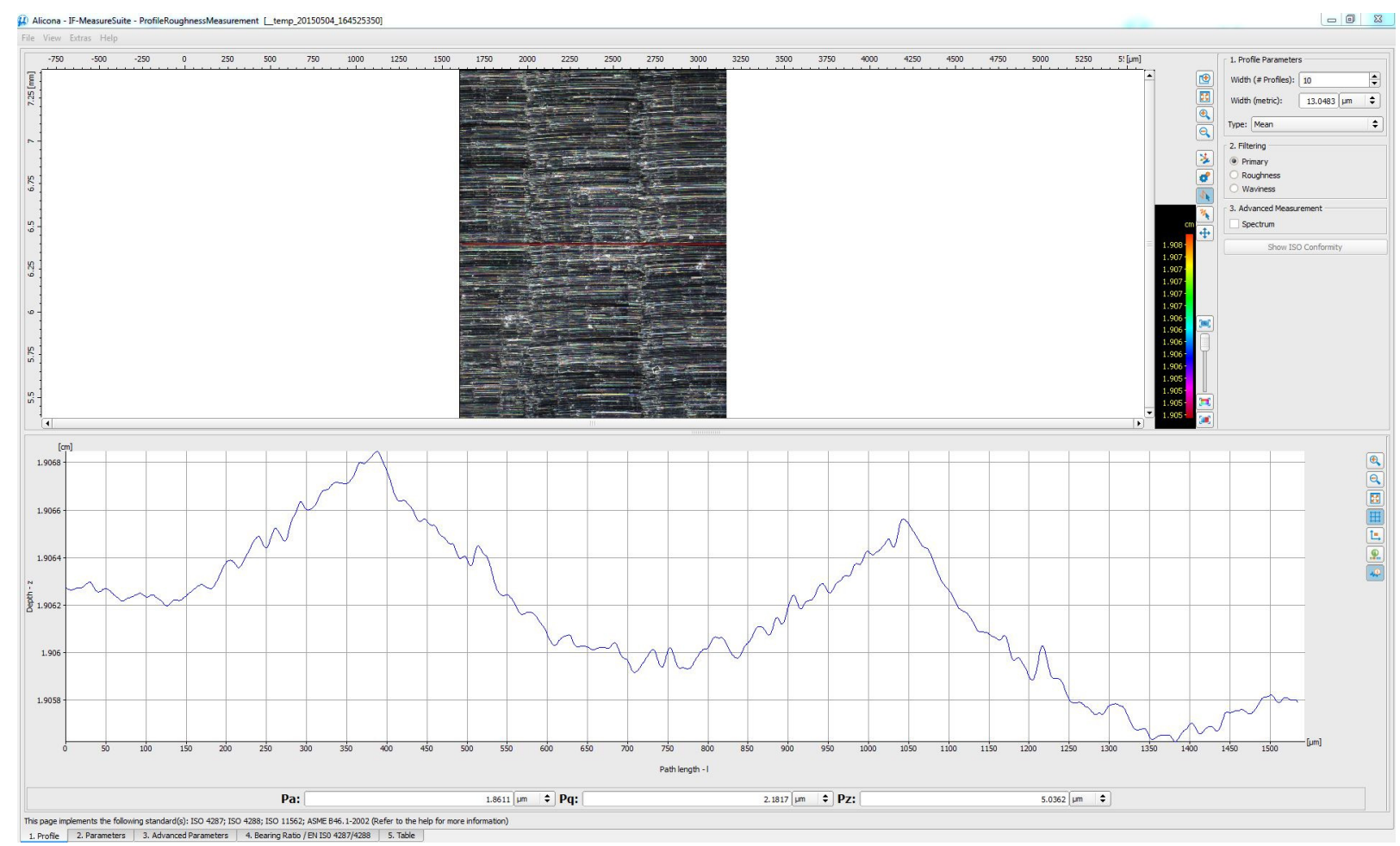

Figure 12. Machined part profile measure

on 5-axis machines for both semi-finishing and finishing. The International Journal of Advanced Manufacturing Technology 2000; 16(6): 383-391.

5. Lee YS. Admissible tool orientation control of gouging avoidance for 5-axis complex surface machining. ComputerAided Design 1997; 29(7): 507-521. DOI:10.1016/ S0010-4485(97)00002-X.
6. Monies F, Mousseigne M, Redonnet JM et al. Determining a collision-free domain for the tool in five-axis machining. International Journal of Production Research 2004; 42(21): 4513-4530.

7. Chen X, Zhao J, Dong Y et al. Research on the machined surface integrity under combination of various inclination angles in multi-axis ball end milling. Proceedings of the 
Institution of Mechanical Engineers Part B - Journal of Engineering Manufacture 2014; 228(1): 31-50. DOI: $\{10$. 1177/0954405413496095\}.

8. Senatore J, Segonds S, Rubio W et al. Correlation between machining direction, cutter geometry and step-over distance in 3-axis milling: Application to milling by zones. ComputerAided Design 2012; 44(12): 1151-1160. DOI:10.1016/j.cad. 2012.06.008.

9. Quinsat $Y$ and Sabourin L. Optimal selection of machining direction for three-axis milling of sculptured parts. The International Journal of Advanced Manufacturing Technology 2007; 33(7-8): 684-692. DOI:10.1007/ s00170-006-0515-5.

10. Anotaipaiboon W, Makhanov S and Bohez E. Optimal setup for five-axis machining. International Journal of Machine Tools and Manufacture 2006; 46(9): 964-977. DOI:10.1016/ j.ijmachtools.2005.07.046.

11. Hu P and Tang K. Improving the dynamics of five-axis machining through optimization of workpiece setup and tool orientations. Computer-Aided Design 2011; 43(12): 16931706. DOI:10.1016/j.cad.2011.09.005.

12. Pessoles X, Landon Y, Segonds S et al. Optimisation of workpiece setup for continuous five-axis milling: application to a five-axis $\mathrm{BC}$ type machining centre. International Journal of Advanced Manufacturing Technology 2013; 65(14): 67-79. DOI:10.1007/s00170-012-4151-y.

13. Woo T. Visibility maps and spherical algorithms. Computer-Aided Design 1994; 26(1): 6-16. DOI:10.1016/ 0010-4485(94)90003-5.

14. Lee RS, Lin YH, Tseng MY et al. Evaluation of workpiece orientation and configuration of multi-axis machine tool using visibility cone analysis. International Journal of Computer Integrated Manufacturing 2010; 23(7): 630-639. DOI:10. 1080/09511921003700861.

15. Chiou CJ and Lee YS. A machining potential field approach to tool path generation for multi-axis sculptured surface machining. Computer-Aided Design 2002; 34(5): 357-371. DOI:10.1016/S0010-4485(01)00102-6.

16. Agrawal RK, Pratihar DK and Roy Choudhury A. Optimization of CNC isoscallop free form surface machining using a genetic algorithm. International Journal of Machine Tools and Manufacture 2006; 46(7-8): 811-819. DOI:10. 1016/j.ijmachtools.2005.07.028.

17. Balic $\mathrm{J}$ and Korosec $\mathrm{M}$. Intelligent tool path generation for milling of free surfaces using neural networks. International Journal of Machine Tools and Manufacture 2002; 42(10): 1171-1179. DOI:10.1016/S0890-6955(02)00045-7.

18. Erkorkmaz K, Layegh SE, Lazoglu I et al. Feedrate optimization for freeform milling considering constraints from the feed drive system and process mechanics. CIRP Annals - Manufacturing Technology 2013; 62(1): 395-398. DOI:10.1016/j.cirp.2013.03.084.
19. Chen, JSB and Huang, YK and Chen, MS. Feedrate optimization and tool profile modification for the highefficiency ball-end milling process. International Journal of Machine Tools and Manufacture 2005; 45(9): 1070-1076. DOI: $\{10.1016 / j . i j m a c h t o o l s .2004 .11 .020\}$.

20. Tounsi, $\mathrm{N}$ and Elbestawi, MA. Optimized feed scheduling in three axes machining. Part 1: Fundamentals of the optimized feed scheduling strategy. International Journal of Machine Tools and Manufacture 2003; 43(3): 253-267. DOI:\{10.1016/ S0890-6955(02)00233-X\}.

21. Pessoles X, Landon $Y$ and Rubio W. Kinematic modelling of a 3-axis NC machine tool in linear and circular interpolation. The International Journal of Advanced Manufacturing Technology 2010; 47(5-8, SI): 639-655. DOI:10.1007/ s00170-009-2236-z.

22. Redonnet JM, Djebali S, Segonds S et al. Study of the effective cutter radius for end milling of free-form surfaces using a torus milling cutter. Computer-Aided Design 2013; 45(6): 951-962. DOI:10.1016/j.cad.2013.03.002.

23. Nelder JA and Mead R. A simplex method for function minimization. The Computer Journal 1965; 7(4): 308-313. DOI:10.1093/comjnl/7.4.308.

24. Monies F, Redonnet JM, Rubio W et al. Improved positioning of a conical mill for machining ruled surfaces: application to turbine blades. Proceedings of the Institution of Mechanical Engineers Part B - Journal of Engineering Manufacture 2000; 214(7): 625-634. 